\title{
Prion protein in Alzheimer's disease
}

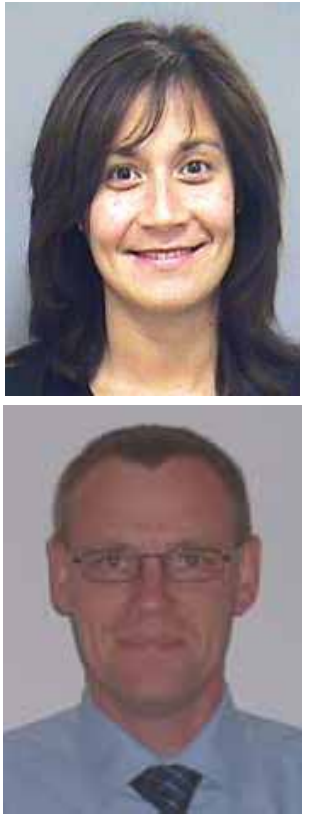

NicoleT Watt $\&$ Nigd M Hogpert

${ }^{\dagger}$ Author for correspondence Institute of Cellular \& M olecular Biology, Proteolysis Research G roup, Faculty of Biological Sciences and,

Leeds Institute of $G$ enetics $H$ ealth \& Therapeutics, U niversity of L eeds, Leeds, LS2 9JT, UK

Tel.: +44 113343 3163; Fax: +44 113343 5638; n.m.hooper@leeds.ac.uk

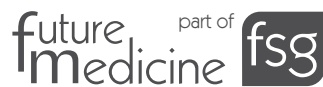

\author{
'...the identific ation of \\ molecules able to mimic or \\ recapitulate these \\ a ntia myloidogenic and \\ antioxida tive functions of PrPc \\ may provide a new avenue \\ for the development of \\ AD thera peutic s.'
}

With the rise in life expectancy, Alzheimer's disease (AD) has become of increasingly significant concern to healthcare professionals and the population as a whole. As the most prevalent mental health issue affecting our aging population, with over 24 million sufferers worldwide and an estimated cost that runs into billions of dollars [101], scientific interest remains prioritized on novel therapeutic strategies. Currently, there remains no adequate treatment to cure or prevent disease progression and only limited options to alleviate some of the symptoms [1]. AD is characterized pathologically by extracellular senile plaques and intracellular neurofibrillary tangles. The major component of the senile plaque is the amyloid $\beta$ $(\mathrm{A} \beta)$ peptide, which is derived from the proteolysis of the large transmembrane amyloid precursor protein (APP). Cleavage of APP by $\beta$-secretase ( $\beta$-site APP-cleaving enzyme [BACE]1) is the first step in releasing neurotoxic $A \beta$ peptides; $A \beta_{1-40}$ is the most prevalent form, whilst $A \beta_{1-42}$ is more fibrillogenic and is the major species found in the senile plaques [2]. Rapid advances are being made to further understand the pathological development of $A D$, particularly relating to the roles of cellular proteins in the production, aggregation and metabolism of $A \beta$ [1].

The prion protein (PrP) is the causative agent of the transmissible spongiform encephalopathies (TSEs), which include scrapie in sheep, bovine spongiform encephalopathy or 'mad cow disease' in cattle and C reutzfeldt-Jakob disease, Gerstmann-Straussler-Scheinker disease and fatal familial insomnia in humans [3]. In TSEs, the normal cellular isoform of $\operatorname{PrP}(\operatorname{PrPC})$ undergoes a post-translational conformational change to create the infectious, disease-causing isoform $\operatorname{PrPSC}^{[4]}$. Whilst being an absolute prerequisite for disease propagation by providing the substrate for conversion, a precise physiological role for PrPC remains uncertain, especially as knockout mice in which the gene encoding PrP has been ablated are without gross anatomical defect or overt pathology. H owever, growing evidence indicates that $\operatorname{PrPC}$ may have a role in neuronal defence against oxidative stress, either by direct chelation of redox-active metal, as a sacrificial molecule or as a copper-sensitive stress sensor [4].

$\mathrm{H}$ ere, we summarize recent data demonstrating a direct role for $\mathrm{PrPC}$ in regulating the production of the $A \beta$ peptide and, potentially, the progression of $A D$. As oxidative stress is an early event in the pathogenesis of $A D$ and as $\mathrm{PrPC}$ can protect cells against oxidative stress, we highlight this link, and speculate whether molecules capable of mimicking the antiamyloidogenic and antioxidative functions of PrPC may provide a novel approach in the treatment of $A D$.

Protective role for $\mathrm{PrPC}$ in

Alzheimer's disease

Recently, we reported that increasing the amount of $\mathrm{PrPC}$ within neuronal cells dramatically inhibited the formation of both $A \beta_{1-40}$ and $A \beta_{1-42}$ [5]. Conversely, reducing the amount of $\operatorname{PrPC}$ in cultured neuronal cells through the use of small interfering RNAs resulted in an increase in $A \beta$ production, while the brains from PrP-knockout mice had increased $A \beta$ levels compared with mice with normal amounts of PrPC $[5]$.

' $\mathrm{PrPC}$ has a role in regulating the production of the neurotoxic $A \beta$ peptide and, hence, protecting against AD.'

Together, these observations indicate that $\mathrm{PrPC}$ has a role in regulating the production of the neurotoxic $A \beta$ peptide and, hence, protecting against $A D$ (Figure 1). Further analyses of the metabolism of APP revealed that PrPC was regulating the production of $A \beta$ at the first step in the proteolytic processing of APP, which is carried out by BACE1. H owever, PrPC did not alter the 


\section{Figure 1. Protective role for $P r P C$ in Alzheimer's disease.}

Cause, e.g., aging,

oxidative stress

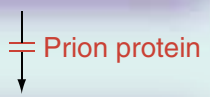

Amyloid- $\beta$ peptide

accumulation
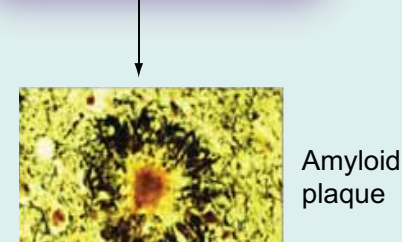

20, 19020

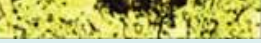

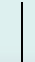

Dementia

(1)

$\downarrow$

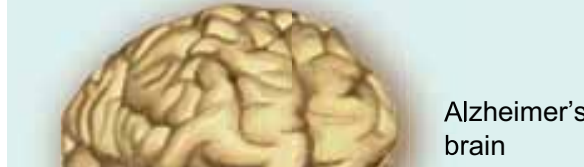

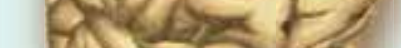

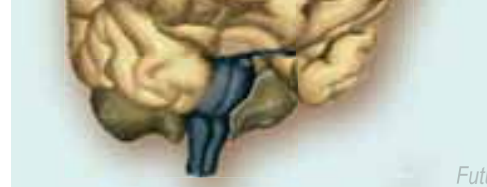

amount of BACE1 in the cells nor did it directly inhibit its catalytic activity towards a short synthetic peptide substrate. Coimmunoprecipitation studies indicated that PrPC interacted directly with BACE1, and the use of mutants of $\mathrm{PrPC}$ revealed that this interaction was glycosaminoglycan-dependent and required PrPC to be localized in cholesterol-rich domains of the cell membrane [5]. Further investigation of the mechanism by which PrPC inhibits the cleavage of APP by BACE 1 may provide the opportunity for the design of novel $\mathrm{PrPC}$ agonists that mimic this effect and that would have therapeutic potential for $A D$.

This novel role for $\operatorname{PrPC}$ in inhibiting the cleavage of APP by BACE1, thereby regulating the production of the neurotoxic $A \beta$ peptide (Figure 1), raises the possibility that a small reduction in the level of functional PrPC in individuals may increase the amyloidogenic processing of APP in a subtle way over decades to affect long-term $A \beta$ production, which in turn could accelerate the deposition of amyloid in the brain and the onset of AD. Further studies are required to address this hypothesis. H owever, if true, one would predict that complete absence of PrPC in humans would lead to the onset of $A D$ at a relatively early age as there would be no PrPC to regulate the BACE 1 cleavage of $A P P$, with the result that the production of $A \beta$ would be higher throughout life. Support for this hypothesis comes from two familial prion diseases that are due to mutations ( $\mathrm{Y} 145^{\text {stop }}$ and $\mathrm{Q} 160^{\text {stop }}$ ) in $\mathrm{PrPC}$, which result in truncated proteins that are rapidly metabolized by the cell $[6,7]$. In both cases, the onset of clinical disease occurred in the fourth decade of life and, in the $Y 145^{\text {stop }}$ case, a diagnosis of $A D$ was initially made [6]. Thus, these natural mutations in $\mathrm{PrPC}$ provide compelling evidence that the loss of functional PrPC in humans may lead to the early onset of $A D$.

\section{Oxidative stress in Alzheimer's disease}

In addition to the direct effect of $\operatorname{PrPC}$ on the production of $A \beta$ outlined above, it is also important to consider that $A D$ is a disease of aging, a phenomena associated with an increase in reactive oxygen species (ROS) [8]. Oxidative stress occurs when the rate at which a cell produces ROS is outweighed by the inherent ability of the cell to quench them. A substantial body of evidence exists to demonstrate that oxidative stress is an early event in the pathogenesis of AD (Figre 1) and is present even before the hallmark features of AD are detectable [9].

'...natural mutations in PrPC provide compelling evid ence that the loss of functional PrPC in humans may lead to the early onset of AD.'

O xidative modification in susceptible neurons of $A D$ has been found in almost all classes of celIular macromolecules, and includes D N A-strand breaks and fragmentation, protein nitration and carbonyl formation and lipid peroxidation [10,11]. Interestingly, oxidative damage decreases with disease progression, such that markers that were elevated during the earlier stages of disease decrease as the disease progresses [12]. This would indicate that while RO S not only cause damage to the cellular infrastructure, they may also provoke physiological responses, such as complementary upregulation of antioxidant defences [12]. Furthermore, the deposition of $A \beta$ may be an attempt at functional adaptation to the 
pro-oxidative environment $[13,14]$. The chelation of redox-active metals within senile plaques and intraneuronal inclusions, along with the demonstration that the neurons containing such inclusions are protected from cell death, indicate that $A \beta$ deposition may have a beneficial effect.

As RO S-mediated damage appears to be a key factor in $A D$ pathogenesis, measures to reduce the oxidant burden within the cell could contribute towards reducing disease etiology. A growing body of evidence indicates a role for PrPC in the protection of neuronal cells against oxidative stress [15]. PrPC appears to provide crucial early detection of ROS in the local environment by undergoing cleavage following exposure to radical species [16]. Cells in which this cleavage of PrPC occurred were able to cope better under oxidative stress.

'...evidence indicates a role for $\mathrm{PrPC}$ in the protection of neuronal cells a ga inst oxida tive stress.'

H owever, if the protein was unable to undergo cleavage, for example owing to disease-associated mutation, the cells remained compromised [16]. This substantiates a normal physiological function for $\mathrm{PrPC}$ in upregulating the antioxidant defence of neuronal cells. Interestingly, the expression level of $\mathrm{PrPC}$ increases with age [17], suggesting that a physiological mechanism may be in place to reduce the consequence of age related adventitious ROS production. Furthermore, aging mice showed impairment of both short- and long-term memory retention when there was an absence of PrPC [18].

\section{Conclusion}

Taken together, these data suggest that the beneficial effect of PrPC may be at least twofold; as a direct cellular inhibitor of the amyloidogenic processing of APP to produce the neurotoxic $A \beta$ and as a key component of the cellular protection against oxidative stress. As both $A \beta$ and oxidative stress are intimately associated with the development and progression of $A D$, then it follows that PrPC may have a fundamental role to play in protecting against this devastating neurodegenerative disease. In the future, the identification of molecules able to mimic or recapitulate these antiamyloidogenic and antioxidative functions of PrPC may provide a new avenue for the development of $A D$ therapeutics.

\section{Future perspective}

The discovery of a role for PrPC in regulating the production of the neurotoxic $A \beta$ peptide, and thus in directly protecting against $A D$, as well as its antioxidant role, opens up new avenues for research in coming years. As we learn more about

Executive summary

\section{Introduction}

- Alzheimer's disease (AD) is the major neurodegenerative disease of old age for which there is currently no cure.

- $A D$ is characterized by the build up of the neurotoxic amyloid- $\beta(A \beta)$ peptide, which is deposited in senile plaques in the brain.

- Cellular prion protein ( $\mathrm{PrPC})$, which causes the transmissible spongiform encephalopathies, is involved in the protection of neurons against oxidative damage.

\section{Protective role for the prion protein in Alzheimer's disease}

- In neuronal cells PrPC dramatically inhibits the formation of $A \beta$ through inhibiting the action of the $\beta$-secretase $\beta$-site amyloid precursor protein-cleaving enzyme 1.

- In mice lacking PrPC, the amount of $A \beta$ in the brain is increased, while in humans with mutations in PrPC that lead to lack of functional protein an early diagnosis of AD was made.

\section{Oxidative stress in Alzheimer's disease}

- Aging is associated with an increase in reactive oxygen species and oxidative stress is an early event in the pathogenesis of AD.

- PrPC protects cells against oxidative stress and the level of PrPC in the brain increases with age.

\section{Conclusions}

- $\operatorname{PrPC}$ has beneficial effects, as a direct inhibitor of the production of $A \beta$ and in the protection against the oxidative environment known to promote AD progression.

- Identification of molecules able to mimic or recapitulate the beneficial functions of PrPC may provide a new avenue for AD therapeutics.

\section{Future perspective}

- Such therapeutics could be used alongside drugs already in development and in clinical trials in our battle against the most prevalent and devastating neurodegenerative disease of old age. 
the mechanisms underlying both of these cellular roles of PrPC, it may be possible within 5-10 years to identify and/or develop small molecules that mimic these protective functions. Further ahead, such novel therapeutics could be used alongside drugs al ready in development and in clinical trials in our battle against the most prevalent and devastating neurodegenerative disease of old age.
Financial \& competing interests disclosure Wethank the M edical Research Council of $\mathrm{G}$ reat Britain for financial support of our work. The authors haveno other relevant affiliations or financial involvement with any organization or entity with a financial interest in or financial conflict with the subject matter or materials discussed in the manuscript apart from those disclosed.

No writing assistance was utilized in the production of this manuscript.

\section{Bibliography}

1. Vardy ER, H ussain I, H ooper N M : Emerging therapeutics for Alzheimer's disease. Expert Rev. N eurother. 6(5), 695-704 (2006).

2. M attson M P: Pathways towards and away from Alzheimer's disease. N ature 430(7000), 631-639 (2004).

3. Watts JC, Balachandran A, Westaway D: The expanding universe of prion diseases. PLOS Pathog. 2(3), e26 (2006).

4. Westergard $L, C$ hristensen $H M, H$ arris D A: The cellular prion protein ( $\mathrm{PrPC})$ : its physiological function and role in disease. Biochim. Biophys. Acta 1772(6), 629-644 (2007).

5. Parkin ET, Watt NT, H ussain I et al.: C ellular prion protein regulates $\beta$-secretase cleavage of the Alzheimer's amyloid precursor protein. Proc. Natl Acad. Sci. U SA 104(26), 11062-11067 (2007).

6. Kitamoto T, lizuka R, Tateishi J: An amber mutation of prion protein in Gerstmann-Straussler syndromewith mutant PrP plaques. Biochem. Biophys Res Commun. 192(2), 525-531 (1993).

7. Finckh $U$, M uller-Thomsen $T, M$ ann $U$ et al.: $\mathrm{H}$ igh prevalence of pathogenic mutations in patients with early-onset dementia detected by sequence analyses of four different genes. Am. J. H um. Genet. 66(1), 110-117 (2000).

8. H alliwell $\mathrm{B}: \mathrm{O}$ xidative stress and neurodegeneration: where are we now? J. N eurochem. 97(6), 1634-1658 (2006).

9. Lee H G, Perry G, M oreira PI et al.: Tau phosphorylation in Alzheimer's disease: pathogen or protector? Trends $\mathrm{M}$ ol. M ed. 11(4), 164-169 (2005).
10. Butterfield D A, Reed T, N ewman SF, Sultana R: Roles of amyloid $\beta$-peptideassociated oxidative stress and brain protein modifications in the pathogenesis of Alzheimer's disease and mild cognitive impairment. Free Radic. Biol. M ed. 43(5), 658-677 (2007).

11. Zhu X, Su B, Wang X, Smith M A, Perry G: Causes of oxidative stress in Alzheimer disease. Cell. M ol. Life Sci. 64(17), 2202-2210 (2007).

12. N unomura A, Castellani RJ, Zhu X et al.: Involvement of oxidative stress in Alzheimer disease. J. N europathol. Exp. N eurol. 65(7), 631-641 (2006).

13. Petersen RB, Siedlak SL, LeeH G et al.: Redox metals and oxidative abnormalities in human prion diseases. Acta N europathol. (Berl.) 110(3), 232-238 (2005).

14. Castellani RJ, Lee H G, Perry G, Smith M A: Antioxidant protection and neurodegenerative disease: the role of amyloid- $\beta$ and tau. Am. J. Alzhemers D is 0 ther D emen. 21(2), 126-130 (2006).

15. Vassallo N , H erms]: C ellular prion protein function in copper homeostasis and redox signalling at the synapse. J. N eurochem. 86(3), 538-544 (2003).

16. Watt NT, Taylor D R, Gillott A et al.: Reactive oxygen species-mediated $\beta$-cleavage of the prion protein in the cellular response to oxidative stress. J. Biol. Chem. 280(43), 35914-35921 (2005).

17. Williams W M , Stadtman ER, M oskovitz J: Ageing and exposure to oxidative stress in vivo differentially affect cellular levels of PrP in mouse cerebral microvessels and brain parenchyma. Neuropathol. Appl. N eurobiol. 30(2), 161-168 (2004).
18. Coitinho AS, Roesler R, M artins VR, Brentani RR, Izquierdo I: C ellular prion protein ablation impairs behavior as a function of age. Neuroreport 14(10), 1375-1379 (2003).

Website

101. Alzheimer's Research Trust www.alzheimers-research.org.uk

Affiliations

- NicoleT Watt Institute of Cellular \& M olecular Biology, Proteolysis Research Group, Faculty of Biological Sciences and, L eeds Institute of $\mathrm{G}$ enetics, $\mathrm{H}$ ealth \& $T$ herapeutics, U niversity of $L$ eeds, Leeds, LS2 9JT, UK

Tel.: +44 113343 7729;

Fax: +44 1133435638 .

n.t.watt@leeds.ac.uk

- Nigel M Hooper Institute of Cellular \& M olecular Biology, Proteolysis Research Group, Faculty of Biological Sciences and, L eeds Institute of $\mathrm{G}$ enetics, $\mathrm{H}$ ealth \& Therapeutics, U niversity of $L$ eeds, L eeds, LS2 9JT, U K

Tel.: +44 113343 3163;

Fax: +44 113343 5638;

n.m.hooper@leeds.ac.uk 